\title{
Biotechnology, Fermentation
}

National Cancer Institute

\section{Source}

National Cancer Institute. Biotechnology, Fermentation. NCI Thesaurus. Code C18656.

Development of fermentation processes for the biotech industry. 